\title{
Ueber Glycolylsulfoharnstoff;
}

\author{
von J. Volhard.
}

Im Anzeiger der k. Akad. d. W. zu Wien 1873, Nr. 6, wird eine Abliandlung Maly's über Derivate des Sulfoharnstoffs angekündigt und deren Inhalt folgendermafsen resumirt : „Durch Einwirkung des Sulfoharnstoffs auf Monochloressigsäure entsteht nach der Gleichung

$$
\mathrm{CS}\left\langle\underset{\mathrm{NH}}{\mathrm{NH}}+\underset{\mathrm{COOH}}{\mathrm{CH}_{2} \mathrm{Cl}}=\mathrm{OH}_{2}+\mathrm{Cs}\left\langle\underset{\mathrm{NH}}{\mathrm{NH}_{2}} \cdot \mathrm{CO} . \mathrm{CH}_{2} \mathrm{Cl}\right.\right.
$$

Monochloracetylsulfoharnstoff. Wird dieser mit Ammoniak oder Barytwasser behandelt, so geht daraus unter $\mathrm{HCl}$ Abspaltung Glycolylsulfoharnstoff hervor, welcher Körper das Sulfoderivat des Hydantoïns ist :

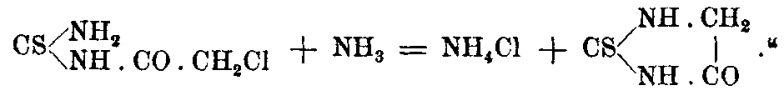

Ich war mit dem gleichen Gegenstand beschäftigt und hatte den Glycolylsulfoharnstoff bereits in Händen, als ich von obiger Notiz Kenntnifs erhielt. Meine Beobachtungen lieferten jedoch ein wesentlich anderes Resultat, als es Maly in den obigen Formeln ausgedrückt hat. Unter den Umständen, unter welchen ich Monochloressigsäure auf Sulfoharnstoff einwirken liefs, nämlich bei gelindem Erwärmen einer Hischung beider Körper im Verhältnifs ihrer MG., bildet sich kein Monochloracetylsulfoharnstoff. Durch eine sehr heftige und von beträchtlicher Wärmeentwickelung begleitete Reaction entsteht ein Körper, welcher zwar die nämliche Zusammenselzung hat wie sie diesem Chloracetylsulfoharnstoff zukommen würde, der aber mit Schwefelsäure in der Kälte unter Aufbrausen salzsaures Gas entwickelt und in Wasser gelöst mit Salpetersäure und Silberlösung den ganzen Chlorgehalt als Chlorsilber fallen läfst; es ist salzsaurer Ğlycolylsulfoharnstoff, der bei langsamem Abkühlen oder beim Verdunsten seiner wässerigen Lösung in schönen wohlausgebildeten Prismen anschiefst. Mit Platinchlorid liefert er ein in spiefsigen Blättchen krystallisirendes Salz $2\left(\mathrm{C}_{3} \mathrm{H}_{4} \mathrm{~N}_{2} \mathrm{OS}, \mathrm{HCl}\right) \mathrm{PiCl}_{4}$ *), auch mit Goldchlorid bildet er ein krystallinisches Doppelsalz. Aus der wässerigen Lösung der salzsauren Verbindung fällen Ammoniak, Alkalien, alkalische

*) Platin gefunden 30,44; 30,14, berechnet 30,63 pC., Schwefel gefunden 9,58 , berechnet $9,93 \mathrm{pC}$. 
Erden, caustisch oder kohlensauer, in der Kälte den Glycolylsulfoharnstoff*), der aus heifsem Wasser oder verdünntem Weingeist in langen glänzenden Nadeln krystallisirt und in Salzsäure gelöst wieder das salzsaure Salz bildet, aus welchem er abgeschieden wurde.

Wendet man bei obiger Reaction auf 1 MG. Sulfoharnstoff 2 MG. Chloressigsäure an, so erhält man ein anderes Product, das sich in Wasser nur zum kleinen Theil auflöst. Es ist das salzsaure Salz einer weniger basischen Verbindung, welches aus stark salzsaurer Lösung in grofsen wasserhellen glänzenden rhombischen Tafeln krystallisirt. Dieses salzsaure Salz wird schon durch Wasser zersetzt unter Abscheidung der krystallinischen, in Wasser kalt und warm kaum auflöslichen Basis.

Der Glycolylsulfoharnstoff wird durch Kochen seiner Lösung mit Blei- oder Quecksilberoxyd nicht entschwefelt, schwierig auch durch Jod, leicht durch Brom, sehr leicht durch Quecksilberoxyd bei Gegenwart von Ammoniak.

Ich denke nicht daran, Maly die Entdeckung des Glycolylsulfoharnstoffs streitig zu machen; andererseits halte ich mich um so mehr für berechtigt, meine unabhängig von $\mathrm{M}$ aly begonnene Untersuchung fortzusetzen, als ich dieselbe hauptsächlich zun Zweck des Studiums der Entschwefelungsproducte dieser Körper hegonnen habe.

München, 12. März 1873.

$\begin{array}{lcc}\left.{ }^{*}\right) & \text { Gefunden } & \text { Berechnet }\left(\mathrm{C}_{3} \mathrm{H}_{4} \mathrm{~N}_{2} \mathrm{OS}\right) \\ \mathrm{C} & 31,92 & 31,03 \\ \mathrm{H} & 3,95 & 3,45 \\ \mathrm{~N} & 24,18 & 24,14 .\end{array}$

Ausgegeben am 24. März 1873. 